\title{
TRANSLANGUAGING FOR EPISTEMIC ACCESS TO COMPUTER SCIENCE CONCEPTS: A CALL FOR CHANGE
}

\author{
Vimbai Mbirimi-Hungwe \& Taurai Hungwe \\ Sefako Makgatho University of Health Sciences.
}

\begin{abstract}
Multilingual education has seemingly been relegated to English and academic literacy lecturers in South African universities. This paper reports on the use of translanguaging in a multilingual second-year computer science class. Using descriptive statistical analysis as well as qualitative analysis, results showed that students perceived translanguaging to be a helpful pedagogical strategy that could be used to assist them to gain deeper meaning and understanding of difficult concepts in their field of study. The research also showed and proved that, for translanguaging to become relevantly useful to the students, all members of the faculty should be involved in using this pedagogical strategy in the classroom. Therefore, we argue that, through collaborative efforts by using translanguaging among lecturers from different faculties, students will be able to acquire deeper meaning and understanding of subject material, especially in content-based courses or modules.
\end{abstract}

Keywords: translanguaging, multilingualism, pedagogical purposes, collaboration

\section{INTRODUCTION}

Academic failures, poor reading comprehension and reading skills have been among major complaints by lecturers in institutions of higher learning worldwide (Crabtree \& Silver, 2004). South African universities are no exception in this matter. According to a study conducted by the Council for Higher Education (CHE) in 2009, $70 \%$ of undergraduate students drop out or are excluded at the end of the first year. In addition to the dropouts, many students fail one or more courses or pass marginally. This suggests that many students lack an adequate grasp of their areas of study (Scott, 2009). In South African universities, a significant factor responsible for the high failure rate is the perceived poor basic education. This culminates in low literacy levels in the language of learning, which is predominantly English for most students (Ngcobo, 2014 : 124). In addition to English being their second or third language, these students are expected to read, understand and perform academic tasks in English. This shows that there is a problem that needs to be redressed.

The purpose of this paper is to explore student perceptions about the use of translanguaging as a strategy to help students to understand computer science concepts.

Recently, translanguaging has been seen as the 'possibility model' (Harfenick \& Wiant, 2012) of encompassing multilingual students into the academia. The 'possibility model' emanates from the need to reject the 'deficit model' of bringing remedial strategies to multilingual students. Rather, it is important to use translanguaging as a vehicle to ensure student success.

By definition, translanguaging is a pedagogical practice where students are asked to alternate languages for the purpose of receptive or productive use (Williams, 1996 :45). Wei (2016:3) further describes translanguaging as a pedagogical practice where students receive 
information through the medium of a different language (e.g., English) and give information through another language (e.g., Sepedi) in order to maximise their learning and understanding of concepts. Thus, translanguaging is a pedagogic practice not meant to be utilised by English lecturers only; rather, lecturers from all faculties can use it productively in multilingual classrooms to help students gain a deeper understanding of concepts in various areas of study.

In addition, translanguaging is concerned with ensuring that students are able to make meaning and attain a deeper understanding of learned material through the utilisation of all languages at their disposal (Garcia, 2009a; Garcia \& Wei, 2014; Makalela, 2015; Wei, 2016). Thus, translanguaging posits a student-centred approach to teaching to ensure that students understand and make meaning out of learned material.

The multilingual nature of South African universities is entrenched in the constitution, where 11 most-spoken languages were adopted as official languages. A number of official policy documents and government documents outline the status and role of various languages in South Africa. In particular, legislation in higher education recommends that higher education institutions (HEIs) should promote the use of African languages. This is an acknowledgement of the multilingual nature of South African universities. In addition, the policy requires all HEIs to advance the official South African languages. The Language Policy of Higher Education (Department of Education, 2002) recommends that universities make provisions to assist students who speak languages other than those used for tuition to develop academic literacy (Department of Education, 2002). The recommendation is due to acknowledgement by the Department of Education that language should not act as a barrier to equity of access and success. Consequently, the policy also mandates South African universities to develop and nurture all South African languages so that they can be formally used in all academic disciplines. Furthermore, in order to acknowledge the importance of using and nurturing all South Africa languages in HEIs, the policy recommends the development of multilingual dictionaries and other teaching and learning materials in order to promote all 11 official languages. The policy provides recommendations that point to the need for a comprehensive development of African languages for the academic benefit of students speaking languages other than the language of teaching and learning. This consideration is also due to the fact that African languages have not developed to become academic languages, but the majority of students entering into university are not fully proficient in English - they require the use of their home languages to understand some academic concepts (Van Der Walt, 2004 :141).

Despite the clear policy of multilingualism, a tacit policy of monolingualism is still in place, especially in historically black universities (Kotze, 2013; Makalela, 2014). Makalela and McCabe's (2013) findings on the University of Limpopo's language policy indicated that the university had not made noticeable progress in terms of putting in place a firm language policy. Neither had there been an attempt to use any of the dominant languages spoken by students. Makalela and McCabe (2013) found that, despite the university's enrolment of predominantly black students who speak Xitsonga and Sepedi, the university had not put in place measures to ensure the use of these languages academically. This was also the case with Sefako Makgatho Health Sciences University, where Sepedi and Setswana students were in the majority. However, Makalela and McCabe (2013 :408) argue that multilingualism is an available resource that universities need to utilise effectively in order to increase multiple competencies inherent in the discourses of the students.

HEIs have generally argued that global competitiveness is best served by an education that is conducted in English, which is the language of the global market (Hibbert \& Van der Walt, 
2014:7). This argument neglects the fact that most students who enter university come from educationally disadvantaged backgrounds and English is not their first language. The students have low academic reading proficiency for them to cope with the academic linguistic demands. It is also at this point important to note that, in addition to students being academically ill-prepared, they come from different linguistic backgrounds, hence the need for a multilingual pedagogy in South African HEIs. Thus, the imposition of monolingualism is no longer relevant in the current academic landscape. Harfenick and Wiant (2012) emphasise the need for lecturers to reject the assumption that the 'norm' on university campuses should be a monolingual English speaker. Instead, they, argue for the need for a new vision and new strategies for integrating multilingual students into academia.

Research in South Africa and internationally has shown the cognitive and academic benefits of using translanguaging in multilingual classrooms (Boakye \& Mbirimi-Hungwe, 2015; Garcia \& Kleyn, 2016; Lewis, Jones \& Baker, 2012; Madiba, 2014; Makalela, 2014). Moreover, research has also shown that students do use translanguaging as a strategy to negotiate understanding, co-construct meaning and to include others (Canagarajah, 2011; Garcia, 2009b; Hibbert \& Van der Walt, 2014; Mashiyi, 2013; Van der Walt \& Dornbrack; 2011; Van der Walt, Mabule \& De Beer; 2001). Mbirimi-Hungwe (2016) reports on a study that was conducted at the University of Limpopo where summary writing using translanguaging was proved to be a measure of reading comprehension. Evidently, translanguaging is a useful pedagogical strategy that can be used to propel students' academic abilities by enhancing the deeper meaning of content material and critical thinking (Lewis, Jones \& Baker, 2012). In this regard, Canagarajah (2006) emphasises the need for lecturers to respect and value the linguistic peculiarities students may display rather than suppressing them for the benefit of the students.

Available evidence through research has shown English language teachers taking the initiative to use translanguaging in multilingual classrooms to enhance students' deeper understanding of the subject material (Harfenick \& Wiant, 2012). In South Africa, lecturers in language departments have been actively involved in using translanguaging with students from other departments. Madiba (2014) reports on a research on concept literacy using translanguaging with Economics students. Makalela (2014) reports on a research conducted at the University of the Witwatersrand School of Education in the languages department. Although these initiatives are commendable, there is a need for lecturers from other faculties to also use translanguaging in their classrooms. This assertion is based on a study conducted by Lopez, Guzman-Orth and Turkan (2014), which showed how students benefitted when they were allowed to use both English and Spanish in a mathematics examination. The results showed that translanguaging of this nature allowed students to utilise their full linguistic repertoire to answer the questions and demonstrate their knowledge in mathematics even though their English was still developing. This research was conducted in the United States where Spanish migrant students were allowed to use both Spanish and English to understand mathematical concepts.

Thus, translanguaging should not be a tool solely used by English language lecturers. Other faculties need to collaborate with colleagues from English language departments and utilise translanguaging in their teaching, as all content subjects undoubtedly have concepts that students struggle to understand in English. Consequently, if students are allowed to use translanguaging, they will have a deeper understanding of such concepts. With this in mind, this paper reports on research conducted by one computer science lecturer and a lecturer from 
the English department. The aim was to establish the effectiveness of using translanguaging to assist students to understand computer science concepts.

\section{RESEARCH CONTEXT}

This research was prompted by a discussion between two colleagues - a lecturer in the computer science department and a lecturer in the English department at a South African university. One of the colleagues was finding it difficult to help his students doing BSc Computer Science to grasp concepts in one of the courses that he was teaching. The course had many technical and abstract terms that were difficult for students to understand. This lecturer pointed out the difficulties students faced in understanding the computer science terms, as well as the fact that the students were not first-language speakers of the English language and were consequently not proficient in the English language.

Research conducted by Oyoo and Semeon (2015 :42) suggests that the struggle in science subjects for South African students begins at school level. This is evidenced by poor performance by South African students on global and international platforms. Oyoo and Semeon (2015:44) point out that Grade 12 students struggle to understand non-technical terms in science, which results in students performing dismally in science. They further point out that most learners are not English first language speakers; therefore, they need support to succeed in their studies.

In addition to the challenges of learning through a language in which they are not proficient, the scientific discourse poses a challenge for students in that it contains many unfamiliar technical words (Probyn, 2015:218). Moreover, conventional words have specialised scientific meanings in computer science. For example, the word 'pipelining' has a different meaning from the commonly known noun 'pipeline'. Therefore, learning science involves a cognitive shift from the common understanding of the world to a scientific view of the world (Probyn, 2015).

With this background, the lecturer from the English department took the opportunity to introduce translanguaging to her colleague. After much discussion, we embarked on a research to find out the effectiveness of using translanguaging to help computer science students experience a deeper understanding of concepts.

\section{THE STUDY}

The aim of the study was to find out whether the use of glossaries through translanguaging would help students to understand difficult concepts. In addition, the study aimed at investigating student perceptions about the use of translanguaging to understand concepts.

\section{THE CONTEXT AND PARTICIPANTS}

The study was conducted among second-year BSc Computer Science students at a South African university. These students take a module called Computer Organisation and Architecture at second-year level. This module requires students to have taken prerequisite modules at first-year level. This means that the second-year module builds on content from the first-year modules where some of the concepts were introduced. Despite these students being taught the background knowledge in first-year modules, they still struggle to understand some of the concepts at the second-year level. 
The major hurdle that confronts these students is the understanding of the technical components of this module. Oyoo and Semeon (2015) define technical components as words specific to the subject. Thus, the technical components in this module are related to computer organisation and architecture. Words such as 'pipelining' and 'branch prediction' (Null \& Lobur, 2015; Stallings, 2016) are among the most commonly used terminology, and they also require deep understanding in order for the students to succeed in the module. In addition to the technical component of the module, students are exposed to non-technical words. These are words that have different meanings when used in a science context (Oyoo \& Semeon, 2015). In this module, students are exposed to words such as 'function', 'memory' and 'shells' (Null \& Lobur, 2015; Stallings, 2016); therefore, students need to be contextually proficient for them to understand and grasp the meaning of such words.

Students are given a course outline at the beginning of the semester and topics to be covered are outlined weekly as per lecture. The outline helps to guide and provide information about content that will be covered every week during lectures. In this study, students were required to identify the key terms used in computer architecture. The lecturer provided the meaning and use of these terms in English. In order for students to show their understanding of the terms and concepts, they would write the meanings of these keywords and concepts in their home languages. Students were allowed to use examples of what they knew in their language that related to the meaning of the terms. To further help students to understand the concepts, students were asked to present their understanding of concepts in class. This was done in their home languages. However, English was also allowed to be used in the discussion whenever the need arose.

\section{RESEARCH DESIGN}

A questionnaire with a four-point Likert-scale section and an open-ended question section was used for the study. There were 10 questions in the four-point Likert scale section, with responses ranging from strongly agree (1) to strongly disagree (4), and three questions in the open-ended section. Before conducting the research, a pilot study was conducted. The pilot study was used to identify the shortcomings of the instrument and these were corrected in the actual study.

\section{DATA COLLECTION}

Students were divided into groups based on their home languages. A total of 11 languages were spoken by the students, namely: Afrikaans, English, IsiNdebele, IsiXhosa, IsiZulu, Sepedi, Setswana, Shona, Siswati, TshiVenda and Xitsonga. Students identified computer science technical terms that were to be used in the module. The lecturer provided a column with English descriptions/explanations of the terms. Another column was left for the students to provide explanations in their language practices. They were allowed to provide examples in their own languages that would enhance their understanding of the terms as well. They were expected to present their understanding of the terms in their languages to the rest of the class. This was done during lecture times.

The questionnaire was distributed to 40 students to respond, and 39 students responded to the questionnaire in the research. The data were analysed quantitatively using descriptive statistical analysis for the closed-ended responses, and qualitative analysis was used for the open-ended responses using recurrent themes. Figure 1 provides a summary of the languages. 


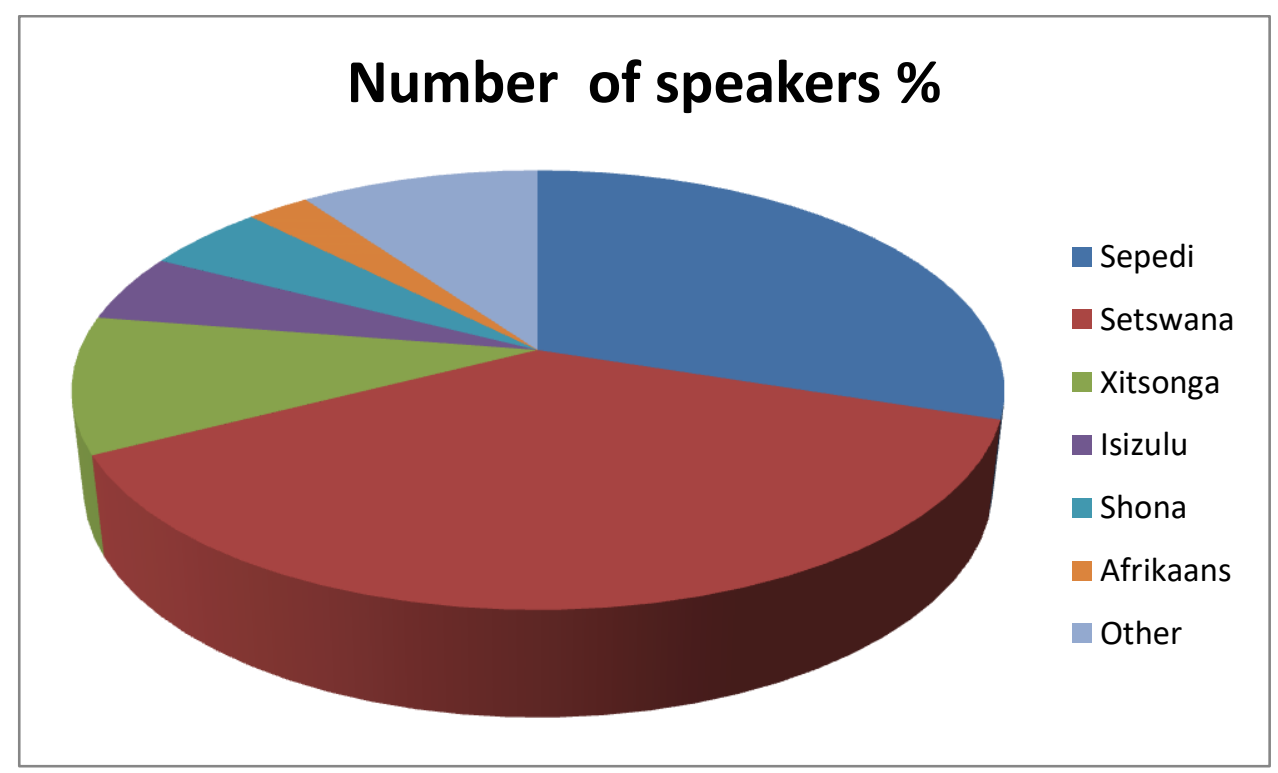

Figure 1: Percentage of students per language spoken

\section{Results from the closed-ended questions}

The closed-ended section asked for participants' linguistic profile. The first question required participants to state all the languages they could speak. Table 1 provides a summary of the number of languages the participants indicated that they could speak.

Table 1: Number of languages spoken by students

\begin{tabular}{|c|c|}
\hline Number of languages & Number of students \\
\hline 2 & 10 \\
\hline 3 & 9 \\
\hline 4 & 9 \\
\hline 5 & 4 \\
\hline 6 & 5 \\
\hline 7 & 2 \\
\hline 11 & 1 \\
\hline
\end{tabular}

From the summary, it can be suggested that participants in this research could speak at least two languages. Results also showed that $75 \%$ of students who participated in this research possessed more than two languages in their repertoire. In this regard, it should be emphasised that multilingualism should be used as an advantage for students to understand concepts. A possibility model of multilingualism should be adopted in the current academic landscape (( Harfenick and Wiant, 2012:18).

The closed-ended section of the questionnaire had 10 questions with which participants were required to either agree or disagree. The questions mainly asked participants' perceptions of the use of translanguaging for learning purposes.

The trend for all the closed questions, which are given as V1 (variable 1) to V10, was that the students agreed or disagreed about the intervention that was used. The results showed that students agreed mostly with the benefits they noticed from using translanguaging as a pedagogical practice for them to understand computer science concepts. As an example, V4 sought to find out whether participants agreed that, even though their home languages may 
not have the vocabulary for most computer science concepts, they still understood these concepts better by using their home languages to explain. Results showed a high number $(85 \%)$ of participants agreeing that they benefitted from this intervention. Thus, this calls for a shift in lecturers' perceptions. Lecturers need to consider including a translingual approach in their teaching. A student-centred approach needs to be adopted as opposed to matching world English standards. We emphasise that it is important for students to understand concepts using their full linguistic repertoires.

In addition, V6 asked participants whether they could still understand concepts in English even though they used their home language to explain the key terms. Many of the students (79\%) affirmed that they could understand the terms fully in English when they read from the textbook. From this example, it can be seen that using translanguaging does not disrupt students' learning in English, which is the language of teaching and learning at university. Rather, using students' linguistic repertoires to understand concepts actually supports proficiency in the target language, which is English (Lewis et al., 2012 :657). In this regard, we argue that lecturers should allow students to utilise the linguistic resources that they possess to support deep understanding of concepts as well as scaffolding their proficiency in English. A monolithic bias towards English will result in an unending outcry among lecturers about students' poor academic performance. It is important for lecturers to view the students' language practices as assets that can propel their learning propensities.

V8 asked whether the opportunity to explain concepts in their own languages made the respondents feel confident. The majority of respondents (79\%) agreed with this notion. It is important for lecturers to note that, as long as students' full linguistic repertoires are silenced in favour of English, social injustice is being done to the students. We refer to 'fluidity' and the 'fuzzy' boundaries of languages, where multilingual beings have languages fluidly accommodated in their repertoires (Garcia, Flores \& Woodley, 2012; Makalela, 2014; Wei, 2016). Silencing some language practices possessed by students by insisting on the use of English only for learning purposes results in social injustice and a disregard for students' linguistic identity. This disadvantages students' learning potential.

Figure 2 presents the aggregated data on respondents' agreement and disagreement with the 10 variables. The figure shows that there were more students who agreed with the translanguaging strategy than those who disagreed. 


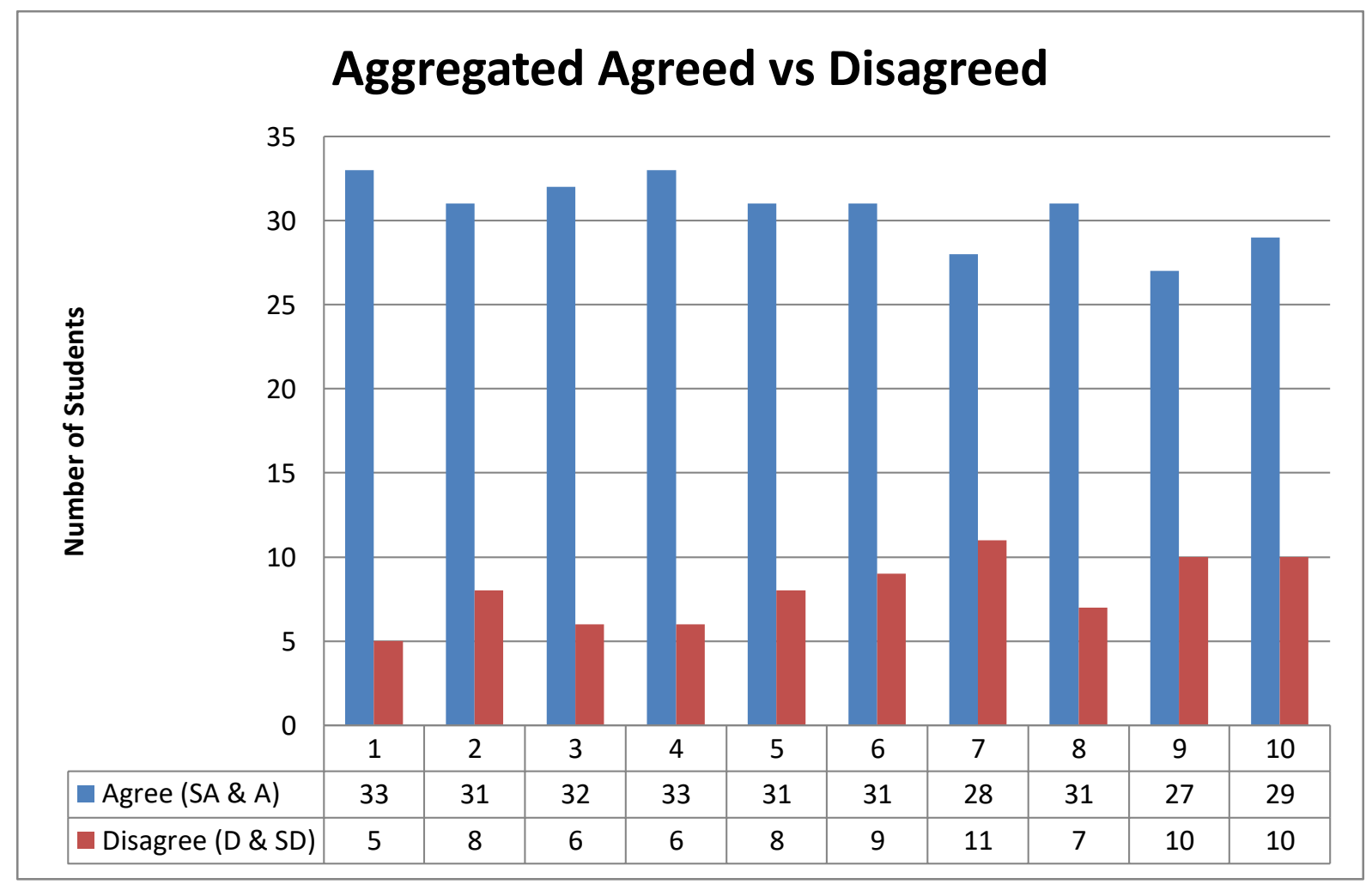

Figure 2: Aggregated agreement vs disagreement

With the Likert-scale collapsed to show both 'strongly agree' and 'agree' responses as 'agree', while using 'disagree' for both 'disagree' and 'strongly disagree' responses, a minimum of $69 \%$ were in agreement with the use of translanguaging, as captured in Figure 2 above.

\section{Results from the open-ended questions}

Four themes were identified from the open-ended questions and they are presented as such. Three open-ended questions were used to get respondents' perceptions of using translanguaging to enhance their understanding of computer science concepts. The questions were as follows:

- Question 15: How do you feel when you are allowed to use your mother tongue (and not English only) to express and explain ideas and concepts to your classmates?

- Question 16: Do you think the use of mother tongue for discussion after reading a text helped you to understand concepts better? Please explain why.

- Question 17: Do you think the development of your own glossary of keywords in computer science helps you to understand concepts better? Please explain why.

Using responses to these open-ended questions, the following themes emerged:

Theme 1: Acknowledgement that deeper meaning and understanding was enhanced through the use of translanguaging

This theme emerged from the majority of the responses to the questions. A total of 25 out of the 39 respondents indicated that using their mother tongue to explain concepts helped them to understand the concepts. Many respondents expressed feelings of joy, excitement and relief 
at the opportunity they got to use the languages at their disposal in order to explain concepts. Below are extracts from some of the respondents:

Respondent 2:

Yes. Some words in English are difficult they have hidden explanations but my Mother Tongue made things easier to understand.

Respondent 5:

It did. Now I can understand several concepts without checking for meaning in the textbook. It feels great because I am going to pass Architecture with better marks than any other Computer Science module I did this semester.

Respondent 9:

I feel I have been given an opportunity to understand and explain better the concepts. The opportunity brings a sense of confidence that though the computer is developed in foreign languages I can understand it in my language.

Respondent 12:

YES. WE ARE NOT WALKING DICTIONARIES. Some English words are too deep especially scientific terms so using your Mother Tongue helps us to understand the concepts better.

Respondent 14:

Yes. When I develop my own glossary in my mother tongue I do not cram the words I deeply understand the whole meaning of the concepts.

My own glossary exposes me to everyday words which I never forget.

Respondent 25:

Yes using my own language made it easier to understand the concepts in class. I can use objects I know from my language to make me understand the concepts better.

Using the responses from the participants, it can be affirmed that students find translanguaging as a pedagogic strategy to enhance meaning and deeper understanding of concepts in English (Garcia, 2009a). The computer science students who participated in this research were able to express confidence in themselves because of being allowed to use their languages to understand concepts. This confirms the importance of allowing students to propel their linguistic repertoires for learning and meaning-making (Hopewell, 2011). It is then important for lecturers from all faculties in universities to note that, if students are allowed to use their funds of knowledge by using their full linguistic repertoires, understanding and meaning are enhanced, thereby helping the students to succeed in their academic endeavours.

In some instances, students found themselves in situations where they had to 'cram' content just to pass tests and exams, yet understanding would not have taken place. One respondent in 
this study acknowledged that, when developing a glossary in a translingual manner, a deep understanding of the terms is developed.

When I develop my own glossary in my mother tongue I do not cram the words I deeply understand the whole meaning of the concepts.

It is therefore important to heed to Paxton's (2009) warning that refusing students to utilise their full linguistic repertoires for purposes of learning results in 'rote' learning, which is not beneficial to the students. In addition, it is crucial for lecturers to consider and take note of the need to adopt multilingualism as a resource that can be used to assist students to deeply understand and make meaning out of difficult academic concepts that they might encounter. In the same vein, lecturers should desist from regarding students' knowledge and use of their mother tongue as a deficit; rather, they should view it as an advantage that can assist multilingual students to understand concepts (Canagarajah, 2006, 2011).

It is important for lecturers to note that, when students are allowed to use their entire linguistic repertoire (translanguaging), they are able to bring knowledge based on their experiences in their home languages and culture which in turn helps them to understand concepts in the target language (English) (refer to Respondent 25). In addition, students possess what Garcia and Kleyn (2016) refer to as translanguaging corriente. That is, the use of home language practices for learning purposes is an undercurrent present in multilingual students. Students always refer to what they know and understand in their language for meaning-making of concepts. In the same manner, Wei (2016 :5) refers to 'translanguaging instinct'. This means that using their home language is inevitable among multilingual students when situations arise for them to do so, especially when they need to understand and make meaning of difficult academic concepts. Thus, not allowing students to utilise their mother tongue for meaning-making and understanding of concepts stifles their learning potential (Boakye \& Mbirimi-Hungwe, 2015).

Based on the majority of responses, students benefited from the use of the languages at their disposal for meaning making and deeper understanding of concepts.

\section{Theme 2: Acknowledgement of the help from using translanguaging, but preference for monolingual use of English for learning}

From the sample of students who participated in this research, a few (6 out of 39) indicated that they found the use of translanguaging useful and helpful in enhancing their understanding of concepts. However, there was a belief among these students that English should be the only language used for teaching and learning. Below are extracts from some responses:

Respondent 13:

It did in a sense because using my Mother Tongue made the concept to be stored in the permanent memory. It's something that I would not consider endeavouring in. I have been speaking my home language for years; I enjoy the ability to use English than my Mother Tongue for my improvement of my English.

Respondent 16:

It feels good though not beneficial because English Is the most used language in the world familiarising myself with it instead of my Mother Tongue is suitable. 
It is a fact that English has been accorded a superior status to other languages worldwide. In the academic context, students have been acculturated to believing that English carries the promise of a job, economic progress and social mobility (van der Walt \& Hibbert, 2014). In addition, English is the language of business globally, so it is reasonable for students to want to associate with the English language more than with their home languages. However, it is important to note that there is research available that shows that understanding of concepts is enhanced when one uses one's full linguistic repertoire to engage with the material. According to Lewis, Jones and Baker (2012), one of the cognitive advantages of using translanguaging for pedagogical purposes is that all languages accessible in a multilingual's repertoire are crucial for meaning-making and understanding in the target language (English).

It is also important to note that, even though English may be the target language required for use worldwide, research has shown that when bi- or multilinguals speak or utilise their cognitive abilities, all languages are active in their minds (Garcia \& Wei, 2014). Thus, insisting on the monolingual use of English is ignoring the reality of being bi- or multilingual. Rather, it is better to utilise all the languages at one's disposal for meaning-making and understanding of concepts, as translanguaging is concerned with enhancing the understanding of concepts and meaning-making. In addition, translanguaging does not advocate for the elimination of English for teaching and learning purposes. Rather, translanguaging challenges the language boundaries that have been instituted culturally and politically, resulting in languages becoming bound entities restricted to certain cultures and races (Wei, 2016). In essence, translanguaging transcends language boundaries and advocates the use of all languages fluidly, as long as meaning is made and understanding of concepts is the end result (Lewis et al., 2012). Therefore, lecturers need to acknowledge that students should not be restricted to using English based on the status it is accorded in the society but rather focus on encouraging students to utilise their language practices (English included) for meaningmaking and understanding of concepts. What is required in this regard is to sensitise and advocate for the importance of all languages for teaching and learning purposes.

\section{Theme 3: Not wanting to use their mother tongue because of a lack of proficiency in the mother tongue}

Worth noting is that a group of respondents indicated that they did not want to use their mother tongue because they lacked the required proficiency to be able to understand concepts (4 out of 39). Some of the responses are as follows:

Respondent 17:

Partly maybe with time and if I spoke my Mother Tongue frequently.

Respondent 21:

No. Personally I do not understand my mother tongue.

These respondents indicated that, though they were multilingual, they had not developed the proficiency required for them to understand concepts in their mother tongues. A further enquiry into these students' background showed that they attended schools where the monolingual use of English was practised for teaching and learning. With regard to such students, the question that remains to be answered is whether such a cohort of students has acquired the necessary proficiency in the English language for them to be academically successful. However, if one takes the advice of van der Walt and Hibbert (2014 :207), it may 
be important for lecturers to manage students' perceptions about the inclusion of the other languages that they possess in their linguistic repertoires in order to reverse the monolingual orientation entrenched in them. Therefore, further research and strategies are required in this regard.

\section{Theme 4: English preference over mother tongue for learning purposes}

The fourth and last theme that came out of the open-ended responses to the questionnaire was that a few respondents (4 out of 39) indicated that they did not benefit from using their home languages for learning. Below are some extracts from their responses:

Respondent 11:

No, it makes it worse. I don't feel like I am explaining to them correctly. I prefer English. Mother Tongue for computers concepts is difficult so I prefer to express myself in English.

Respondent 22:

I don't really feel happy about that because I prefer to use English it is the universal language.

This theme was constituted by international students who felt that using English for learning purposes created a middle ground for them, since they could not speak South African languages other than English. However, it is important to note that research has attributed to the academic literacy unpreparedness in many international students. According to Harfenick and Wiant (2012), it is important for lecturers to encourage such students to use their own languages for meaning-making. Even though they may feel no one will understand their language, it should be stressed that what is important is for them to grasp the meaning and to understand concepts (Garcia, 2009a).

\section{CONCLUSION}

This paper presented students' responses to the use of translanguaging to enhance understanding of computer science concepts. Students reported that they did benefit from using their home languages in order for them to understand concepts better. Responses from the students confirmed that they perceived using their home languages to be a vehicle that could help them to understand difficult concepts in computer science. It is also important to note that the use of translanguaging does not require only English language lecturers to utilise it for teaching purposes. We thus recommend all members of faculties to embrace a multilingual 'possibility model' and use translanguaging to assist students in the learning process. The translanguaging pedagogy does not require lecturers to speak all the languages spoken by the students. The focus should be on students' understanding of concepts and not on the lecturer's knowledge of languages. In this regard, we urge and call for change from all lecturers from different faculties to embrace translanguaging as a pedagogical strategy for the benefit of the multilingual students. However, a few students still felt that English was the universal language and the language of conducting business; thus, they preferred using English. The question that requires further research is whether these students fully understand these concepts when not utilising their full linguistic repertoires. 


\section{REFERENCES}

BOAKYE, N \& V MBIRIMI. 2015. Multilingual pedagogy in higher education: lecturers' perceptions of translanguaging in promoting academic literacy. In L Makalela (Ed.), New directions in language and literacy education for multilingual classrooms. Cape Town: CASAS. 153-156.

CANAGARAJAH, S. 2006. Understanding the 'native speaker fallacy': non-linguistic roots, non-pedagogical results. In G Braine (Ed.), Non-native educators in English language teaching. Mahwah, NJ: Lawrence Erlbaum.

CANAGARAJAH, S. 2011. Translanguaging in the classroom: emerging issues for research and pedagogy. Applied Linguistics Review, 2:1-27.

CHADWICK, C. 2012. Language awareness in teaching: a toolkit for content and language teachers. Cambridge: Cambridge University Press.

CRABTREE, H \& JAK SILVER. 2004. Can student retention and progression be improved by active participation in learning? Innovative Learning in Action, 2:11-15.

COUNCIL FOR HIGHER EDUCATION. 2009. Available from www.che.ac.za [Accessed: 13 July 2016].

DEPARTMENT OF EDUCATION. 2001. National plan for higher education in South Africa. Available from www.education.gov.za [Accessed: 13 July 2016].

GARCIA, O \& T KLEYN. 2016. Translanguaging theory and project. In O Garcia \& T Kleyn (Eds), Translanguaging with multilingual students: learning from classroom moments. New York: Routledge. 9-34.

GARCIA, O, N FLORES \& HH WOODLEY. 2012. Transgressing monolingualism and bilingual dualities: Translanguaging pedagogies. In A Yiakoumetti (Ed.), Harnessing linguistic variation to improve education: rethinking education. Volume 5. Oxford: Peter Lang. 45-75.

GARCIA, O. 2009a. Bilingual education in the $21^{\text {st }}$ century: a global perspective. West Sussex: Blackwell.

GARCIA, O. 2009b. 'Education, multilingualism and translanguaging in the $21^{\text {st }}$ Century.' In AK Mohanty, MR Panda, R Phillipson \& T Skutnabb-Kangas (Eds), Multilingual education for social justice: globalising the local, New Dehli: Orien Black Swan. 140157.

GARCIA, O \& L WEI. 2014. Translanguaging language, bilingualism and education. New York: Palgrave Macmillan.

HARFENIK, JJ \& FM WIANT. 2012. Integrating multilingual students into college classrooms: a practical advice for faculty. New York: Multilingual Matters.

HIBBERT, L \& C VAN DER WALT. (Eds.). 2014. Multilingual universities in South Africa. Reflecting society in higher education. Bristol: Multilingual Matters.

HOPEWELL, S. 2011. Leveraging bilingualism to accelerate English reading comprehension. International Journal of Bilingual Education and Bilingualism, 14(5):603-620.

KOTZE, E. 2014. The emergence of a favourable policy landscape. In L Hibbert C van der Walt (Eds), Multilingual universities in South Africa: Reflecting society in higher education. Bristol: Multilingual Matters. 15-26.

LEWIS, G, B JONES \& C BAKER. 2012. Translanguaging: developing its conceptualisation and contextualisation. Educational Research and Evaluation, 18(7):655-670.

LOPEZ, AA, D GUZMAN-ORTH \& S TURKAN. 2014. A study on the use of translanguaging to assess the content knowledge of emergent bilingual students. Paper presented at the annual meeting of the AAAL Annual Conference, Portland, OR, 18-21 March 2017. 
MADIBA, M. 2014. Promoting concept literacy through multilingual glossaries: translanguaging approach. In L Hibbert \& $\mathrm{C}$ van der Walt (Eds), Multilingual universities in South Africa: Reflecting society in higher education. Bristol: Multilingual Matters. 68-80.

MAKALELA, L. 2014. Teaching indigenous African languages: The effects of translanguaging for multilingual development. In L Hibbert $\mathrm{C}$ van der Walt (Eds), Multilingual universities in South Africa: reflecting society in higher education. Bristol: Multilingual Matters. 88-104.

MAKALELA, L. 2015. Moving out of linguistic boxes: the effects of translanguaging strategies for multilingual classrooms. Language and Education, (29)3:200-217.

MAKALELA, L \& R MCCABE. 2013. Monolingualism in a historically black South African university: a case of inheritance. Linguistics and Education, 24:406-414.

MASHIYI, N. 2014. Tertiary educators' reflections on language practices that enhance student learning and promote multilingualism. In L Hibbert \& $\mathrm{C}$ van der Walt (Eds), Multilingual universities in South Africa: reflecting society in higher education. Bristol: Multilingual Matters. 122-145.

MBIRIMI-HUNGWE, V. 2016. Translanguaging as a strategy for group work: summary writing as a measure for reading comprehension among university students. Southern African Linguistics and Applied Language Studies, (34)3:241-249.

NGCOBO, S. 2014. Dual language instruction: its impact on attitudes towards the role of African languages in education. In L Hibbert $\mathrm{C}$ van der Walt (Eds), Multilingual universities in South Africa: reflecting society in higher education. Bristol: Multilingual Matters. 123-144.

NULL, L \& J LOBUR. 2015. The essentials of computer organization and architecture (4th ed.). Burlington, MA: Jones \& Bartlett.

OYOO, S \& N SEMEON. 2015. The place of proficiency in the language of instruction: grade 12 physical science learner's encounter with everyday words in science context. In L Makalela (Ed.), New directions in language and literacy education for multilingual classrooms in Africa. Cape Town: Casas. 39-66.

PAXTON, MIJ. 2009. It's easy to learn when using your home language but with English, you need to start learning language before you get to the concept: bilingual concept development in an English medium university in South Africa. Journal of Multilingual and Multicultural Development, 30(4):354-359.

PROBYN, M. 2015. Pedagogical translanguaging: bridging discourses in South African classrooms. Language and Education, 23(3):218-234.

SCOTT, I. 2009. First-year experience as terrain of failure or platform for development? Critical choices for higher education. In B Leibowitz, A van der Merwe, and S van Schalkwyk (Eds), Focus on first-year success: Perspectives Emerging from South Africa and beyond. Stellenbosch: Sun Press. 1-18.

STALLINGS, W. 2016. Computer organization and architecture: designing for performance (10th ed). Essex: Pearson.

VAN DER WALT, C \& J DORNBRACK. 2011. Academic biliteracy in South Africa higher education: strategies and practices of successful students. Language, Culture and Curriculum, 24(1):89-104.

VAN DER WALT, C, DR MABULE \& JJ DE BEER. 2001. Letting the L1 in by the back door: code-switching and translation in science, mathematics and biology classes. Journal for Language Teaching, 35(2\&3):170-184.

VAN DER WALT, C \& L HIBBERT. 2014. African languages in higher education: lessons from practice and prospects for the future. In L Hibbert C van der Walt (Eds), 
Multilingual universities in South Africa: Reflecting society in higher education. Bristol: Multilingual Matters. 202-219.

WEI, L. 2016. New Chinglish and the post-multilingualism challenge: translanguaging ELF in China. JELF, 5(1):1-25.

WILLIAMS, C. 1996. Secondary education: teaching in the bilingual situation. In C Williams, G Lewis \& C Baker (Eds), The language policy: taking stock. UK: CAI. 3978 .

\section{BIOGRAPHICAL NOTES}

Vimbai Mbirimi-Hungwe is a lecturer in the Department of Language Proficiency at the Sefako Makgatho University of Health Sciences. Her research focus is on the use of translanguaging pedagogy to multilingual students. Her research focus has extended to introducing translanguaging pedagogy to lecturers in the Science faculty.

Taurai Hungwe is a Computer Science (CS) Lecturer at Sefako Makgatho Health Sciences University. He is interested in using a translanguaging pedagogy in Computer Science. 